\title{
HUBUNGAN ANTARA KOMPETENSI DAN KEDISIPLINAN GURU PAK DENGAN MOTIVASI BELAJAR SISWA
}

\author{
Ardianus Hulu* \\ Dosen di Sekolah Tinggi Teologi Biblika Jakarta \\ Diterima: 6 Maret 2020; Disetujui: 26 Maret 2020; Dipublikasikan: 6 April 2020

\begin{abstract}
Abstrak
Penelitian ini dimaksudkan untuk mencari hubungan antara kompetensi dan kedisiplinan guru PAK dengan motivai belajar siswa. Penelitian ini menggunakan metode deskriptif kuantitatif yakni uji analisis dan uji validitas. Penelitian ini dilakukan di SMK Negeri 1 Alasa Nias Utara. daerah asal penulis sendiri, demi meningkatkan kualitas pendidikan agama Kristen, secara khusus di sekolah ini. Hasil dari penelitian menunjukan bahwa kompetensi guru dan disiplin guru akan menumbuhkan motivasi dari peserta didik. Dengan motivasi positf yang dimiliki oleh peserta didik akan memudahkan pencapaian dalam pendidikan.
\end{abstract}

Kata Kunci: Pendidikan, Kompetensi, Disiplin, Motivasi, Guru dan Peserta Didik.

\begin{abstract}
This research was intended to find out the relationship between the competence and discipline of PAK teachers and students' motivation. This research uses descriptive quantitative method, namely analysis test and validity test. This research was conducted at SMK Negeri 1 Alasa Nias Utara. the author's own area of origin, in order to improve the quality of Christian religious education, especially in this school. The results of the study show that teacher competence and teacher discipline will foster motivation from students. With positive motivation possessed by students, it will facilitate achievement in education.

Keywords: Education, Competence, Discipline, Motivation, Teachers and Students.
\end{abstract}

How to Cite: Dr. Ardianus Hulu, M.Pd.K (2020). Hubungan Antara Kompetensi dan Kedisiplinan Guru dengan Motivasi Belajar Siswa, 5 (1):46-55

*Corresponding author:

ISSN 2355-1704 (Print)

E-mail: ardyhulu86@gmail.com 


\section{PENDAHULUAN}

Pendidikan adalah usaha seorang guru dalam pergaulan dengan peserta didik untuk memimpin jasmani dan rohani ke arah kedewasaan. Dalam artian, pendidikan adalah sebuah proses transfer nilai-nilai dari seorang guru kepada peserta didik agar menjadi dewasa dalam segala hal. Pendidikan merupakan masalah yang penting bagi setiap bangsa yang sedang membangun. Upaya perbaikan di bidang pendidikan merupakan suatu keharusan untuk selalu dilaksanakan agar suatu bangsa dapat maju dan berkembang seiring dengan kemajuan ilmu pengetahuan dan teknologi. Beberapa upaya dilaksanakan antara lain penyempurnaan kurikulum, peningkatan kompetensi guru melalui penataran-penataran, perbaikan saranasaranapendidikan, dan lain-lain. Hal ini dilaksanakan untuk meningkatkan kualitas pendidikan bangsa dan terciptanya manusia Indonesia seutuhnya. Berdasarkan fungsi dan tujuan pendidikan nasional yang tertuang dalam UU No. 20 Tahun 2003 (Sisdiknas, pasal 3). Pendidikan nasional berfungsi mengembangkan kemampuan dan membentuk watak serta peradaban bangsa yang bermartabat dalam rangka mencerdaskan kehidupan bangsa serta mengembangkan potensi peserta didik agar menjadi manusia yang beriman dan bertaqwa kepada Tuhan Yang Maha Esa, berakhlak mulia, sehat, berilmu, cakap, kreatif, mandiri dan menjadi warga negara yang demokratis serta bertanggung jawab. ${ }^{1}$

Untuk mencapai tujuan yang diinginkan tersebut, maka dalam lembaga pendidikan formal yaitu sekolah, keberhasilan pendidikan ditentukan oleh keberhasilan pelaksanaan kegiatan belajar mengajar di sekolah.

Penulis sangat tertarik untuk mengadakan penelitian tentang hubungan antara Kompetensi dan Kedisiplinan Guru Pak Dengan Motivasi Belajar Siswa karena:

Pertama, kurangnya motivasi dari peserta didik menjadi salah satu penyebab lemahnya pendidikan di sekolah-sekolah. Sementara kegiatan belajar mengajar sangat dipengaruhi oleh motivasi dari peserta didik untuk belajar dengan sungguh-sungguh. Itulah sebabnya dalam belajar sangat diperlukan adanya motivasi. Hasil belajar akan menjadi optimal, jika ada motivasi dari peserta didik. Motivasi akan senantiasa menentukan intensitas usaha belajar bagi para peserta didik. Bagaimana peserta didik termotivasi dalam belajar banyak ditentukan oleh guru yang mengajar. Untuk membangkitkan motivasi dari peserta didik maka sebagai seorang guru harus memiliki kompetensi yang tinggi, hal ini diperlukan untuk melaksanakan tugas dan fungsinya secara efektif dan efisien.

Kedua, perlunya kompetensi yang dimiliki oleh guru. Kompetensi merupakan salah satu kualifikasi guru yang terpenting. Bila kompetensi ini tidak ada pada diri seorang guru, maka ia tidak akan berkompeten dalam melakukan tugasnya dan hasilnya pun tidak akan optimal. Menurut Barlow, kompetensi guru ialah "the ability of a teacher to responsibly perform has or her duties appropriately." Artinya, kompetensi guru merupakan kemampuan seorang guru dalam melaksanakan kewajiban-kewajibannya secara bertanggung jawab dan layak. Kemampuan guru dalam menjalankan profesi keguruannya yaitu mampu melaksanakan profesinya disebut sebagai guru yang kompeten dan professional.

\footnotetext{
${ }^{1}$ Undang-Undang No. 20 Tahun 2003 Tentang Sistem Pendidikan Nasional.

${ }^{2}$ Muhibbin Syah, Psikologi Pendidikan suatu Pendekatan Baru (Bandung: Remaja Rosdakarya, 1996), hlm. 230.
} 
Ketiga, selain komptensi yang dimiliki oleh seorang guru yang profesional, hal lain yang mendukung motivasi peserta didik untuk belajar dengan adalah kedisiplinan guru. Menurut Ali Imron, "sikap disiplin dalam tugas harus ditanamkan secara terus menerus dan dijadikan sebagai kebiasaan, sebab pada umumnya orang-orang yang berhasil dalam bidangnya sempunyai disiplin yang tinggi. Sebaliknya orang yang gagal umumnya tidak disiplin.",3

Terlebih lagi bagi seorang guru agama Kristen, ia harus mempunyai nilai lebih dibandingkan dengan guru-guru lainnya. Guru PAK, disamping melaksanakan tugas keagamaan, ia juga melaksanakan tugas pendidikan dan pembinaan bagi peserta didik, ia membantu pembentukan kepribadian, pembinaan akhlak disamping menumbuhkan dan mengembangkan keimanan dan ketaqwaan para peserta didik kepada Tuhan Yesus Kristus.

\section{METODE PENELITIAN}

Metode penelitian yang digunakan dalam penelitian ini adalah penelitian kuantitatif deskriptif yakni uji analisis dan uji Penelitian ini dilakukan secara acak kepada pelajar di SMK Negeri 1 Alasa Nias Utara karena dianggap mewakili dua variable yang diteliti yaitu: (1) Kompetensi dan kedisplinan guru, (2) Motivasi belajar siswa. Untuk pengambilan data, peneliti menggunakan 2 jenis kuisioner untuk 2 variabel yang diteliti.

\section{PEMBAHASAN}

\section{Dasar Teologis Pelaksanan Tugas Guru Pak}

Sebelum membahas dasar teologis dalam pelaksanaan tugas dan tanggung jawab guru Pendidikan Agama Kristen, Maka perlu terlebih dahulu dijelaskan pengertian guru secara umum dan guru Pendidikan Agama Kristen. Secara umum definisi guru adalah tenaga pengajar yang dilatih atau dipersiapkan dan dipilih untuk tugas mengajar, sedangkan guru Pendidikan Agama Kristen adalah "seorang pendidik yang mengajarkan Pengetahuan, tentang pokok-pokok ajaran iman Kristen yang dinyatakan Tuhan di dalam Alkitab, yang menentukan, mengarahkan, dan membimbing siswa supaya bertumbuh dalam iman."4 Selanjutnya menurut pendapat Leatha Humes dan Lieke Simanjuntak, bahwa guru Pendidikan Agama Kristen adalah "Seorang yang dipanggil kepada Tuhan Yesus Kristus, ditebus dan menjadi murid yang tetap mengikutinya dan belajar dari-Nya serta ditugaskan untuk membuat anak didik menjadi murid Kristus dan kemudian mengajar mereka melakukan segala sesuatu yang telah diperintahkan Tuhan kepadanya."5

Berdasarkan pengertian guru Pendidikan Agama Kristen di atas, maka, dapat disimpulkan Guru Pendidikan Agama Kristen adalah tenaga pengajar atau pelayan yang dipilih dan dilatih untuk tugas mengajar Pendidikan Agama Kristen. Pengajaran Pendidikan Agama Kristen merupakan pengetahuan tentang pokok-pokok ajaran iman Kristen yang dinyatakan Tuhan dalam Alkitab, yang menentukan, mengarahkan, dan guru membimbing siswa supaya bertumbuh dalam iman yang sungguh-sungguh

\footnotetext{
${ }^{3}$ Ali Imron, Pembinaan Guru di Indonesia (Jakarta : Pustaka Jaya, 1995), 182.

${ }^{4}$ John M Nainggolan. Guru Agama Kristen Sebagai Panggilan dan Profesi (Bandung : Bina Media Informasi, 2007), 8.

${ }^{5}$ Leatha Humes dan Lieke Simanjuntak. Penuntun Guru PAK Sekolah Minggu dan Sekolah Dasar (Jakarta : BPK Gunung Mulia, 1998), 47.
} 
percaya kepada Tuhan, serta mewujudkan iman tersebut di dalam kehidupan seharihari.

Guru Pendidikan Agama Kristen secara umum mempunyai tugas dan tanggung jawab: mengajar, mengasuh dan membimbing hidup rohani siswa. Menurut pendapat Homrighausen dan Enklaar tugas dan tanggung jawab guru Pendidikan Agama Kristen adalah "menjadi penafsir iman; yang menguraikan dan menerangkan kepercayaan Kristen. Gurulah yang menyampaikan harta-harta dari masa lampau kepada siswa." ${ }^{6}$

Dasar Alkitabiah yang mendorong pelaksanaan tugas dan tanggung jawab guru Pendidikan Agama Kristen yang terdapat dalam Injil Matius 28:19-20, "Karena itu pergilah, jadikanlah semua bangsa murid-Ku dan baptislah mereka dalam nama Bapa dan Anak dan Roh Kudus, dan ajarlah mereka melakukan segala sesuatu yang telah Kuperintahkan kepadamu. Dan ketahuilah, Aku menyertai kamu senantiasa sampai kepada akhir zaman. Dasar Alkitabiah ini disebut sebagai Amanat Agung.

Guru Pendidikan Agama Kristen dalam melaksanakan tugasnya terpanggil untuk bertumbuh ke arah pengenalan yang semakin mendalam dan lengkap tentang pribadi Tuhan Yesus yang akan memungkinkan guru Pendidikan Agama Kristen memahami kehendak Tuhan dalam tugas daan tanggung jawabnya. Membawa siswa dalam kepada pengenalan yang sejati akan pribadi dan karya Allah dan Tuhan Yesus sebagai jalan 'kebenaran dan hidup (Yoh. 1:18; 3:16; 14:6; Kis. 4:12).

Guru Pendidikan Agama Kristen bertanggung jawab membawa siswa kepada Kristus, sehingga siswa dapat mengenal dan mempermuliakan serta mengakui dengan lidahnya bahwa Yesus Kristus adalah Tuhan dan juruselamat semua umat manusia yang ada di dunia ini (Flp. 2: 11).

Guru Pendidikan Agama Kristen merupakan orang yang memberikan dirinya secara penuh kepada Tuhan Yesus Kristus dalam melaksanakan tugas dan tanggung jawab. Guru, tidak boleh mengangap bahwa tugasnya mengajar hanya merupakan formalitas saja, tetapi guru harus bersungguh-sungguh dalam melaksanakan tugas dan tanggung jawabnya untuk membawa siswa kepada pengajaran Tuhan Yesus Kristus yang benar dan sejati.

Dengan demikian guru Pendidikan Agama Kristen mempunyai tugas dan tanggung jawab Yang besar dalam pendidikan agama bagi siswa, sebab pendidikan agama tidaklah sama dengan pelajaran lain di sekolah. Guru Pendidikan Agama Kristen bertanggung jawab dan dituntut untuk memiliki keterampilan dalam menyelami seluruh materi pelajaran dan menghubungkannya dengan nilai-nilai iman Kristen, sehingga siswa dapat mengembangkan kepribadian yang utuh, dan mampu mengaplikasikan materi tersebut di dalam kehidupannya sehari-hari. Supaya hal ini dapat terwujud dengan baik maka harus di tunjang oleh kompetensi dan kedisiplinan dari guru PAK.

\section{Hubungan Kompetensi dan Kedisiplinan Guru PAK Secara Bersama-sama Dengan Motivasi Belajar Siswa}

Seorang guru PAK yang memiliki pengetahuan, keterampilan dan sikap yang baik dalam melaksanakan tugas dan panggilannya, akan berusaha menyajikan materi yang telah dipersiapkan dan diprogramkan. Situasi belajar dengan pendekatan, strategi dan media yang tepat akan lebih menarik minat siswa untuk belajar sehingga

${ }^{6}$ Hamrighausen, E. G. Dan I. H. Enklaar, Pendidikan Agama Kristen (Jakarta : BPK Gunung Mulia, 1993), 10. 
dapat memotivasi siswa tersebut untuk menguasai pelajaran yang disampaikan oleh gurunya. Perhatian guru terhadap kemajuan belajar siswa dengan penuh kasih sayang menuntun untuk dapat berhasil dalam belajar, akan memotivasi siswanya untuk lebih giat belajar sehingga memiliki hasil belajar yang diharapkan.

Guru PAK yang profesional, selain kompeten dalam melaksanakan tugas dan panggilannya, juga berusaha untuk menaati seluruh peraturan yang berlaku di sekolah dan menerapkan kedisiplinan belajar terhadap siswanya. Kedisiplinan ini dapat meningkatkan kinerja guru dalam mengajar, sehingga membuat siswa juga semakin termotivasi untuk belajar PAK.

Berdasarkan uraian di atas, dapat diduga bahwa terdapat hubungan antara Kompetesi dan Kedisiplinan guru PAK secara bersama-sama dengan motivasi belajar siswa. Artinya semakin tinggi kompetensi dan Kedisiplinan seorang guru maka semakin termotivasi pula siswa untuk belajar.

Dengan demikian dapat dirumuskan: Pertama, Terdapat hubungan yang positif dan signifikan antara kompetensi guru PAK dengan motivasi belajar siswa. Kedua, Terdapat hubungan yang positif dan signifikan antara kedisiplinan guru PAK dengan motivasi belajar siswa. Ketiga, Terdapat hubungan yang positif dan signifikan antara kompetensi dan kedisiplinan guru PAK secara bersama-sama dengan motivasi belajar siswa.

\section{HASIL PENELITIAN DAN PEMBAHASAN}

Dalam penelitian ini penulis ingin mengungkapkan apakah ada hubungan yang positif dan signifikan antara kompetensi dan kedisiplinan guru PAK dengan motivasi belajar siswa di SMK Negeri 1 Alasa Nias Utara. Membuktikan adanya hubungan yang positif dan signifikan antara kompetensi guru PAK $\left(\mathrm{X}_{1}\right)$ dan Kedisiplinan guru PAK $\left(\mathrm{X}_{2}\right)$ dengan motivasi belajar siswa $(\mathrm{Y})$.

\section{Kompetensi Guru PAK}

Berdasarkan data yang telah dikumpulkan dari variabel kompetensi guru PAK maka di peroleh nilai-nilai seperti pada tabel berikut ini:

Statistics

Kompetensi Guru PAK $\left(\mathrm{X}_{1}\right)$

\begin{tabular}{|l|l|}
\hline \multicolumn{1}{|c|}{ Valid } & 30 \\
Missing & 0 \\
Mean & 119.07 \\
Std. Error of Mean & 2.144 \\
Median & 122.00 \\
Mode & $124^{\mathrm{a}}$ \\
Std. Deviation & 11.741 \\
Variance & 137.857 \\
Skewness & -1.004 \\
Std. Error of Skewness & 427 \\
Kurtosis & .725 \\
Std. Error of Kurtosis & .833
\end{tabular}




\begin{tabular}{|ll|l|} 
Range & & 46 \\
Minimum & & 88 \\
Maximum & & 134 \\
Sum & & 3572 \\
Percentiles & 25 & 112.00 \\
& 50 & 122.00 \\
& 75 & 130.00 \\
\hline
\end{tabular}

a. Multiple modes exist. The smallest value is shown

Dari tabel hasil perhitungan diatas didapatkan skor empiris antara 88 (minimim) sampai dengan 134 (maximum). Nilai Mean (nilai rata-rata) adalah 119,07, nialai Median (nilai tengah) adalah 122 dan nilai mode (nilai yang sering muncul) adalah 124 .

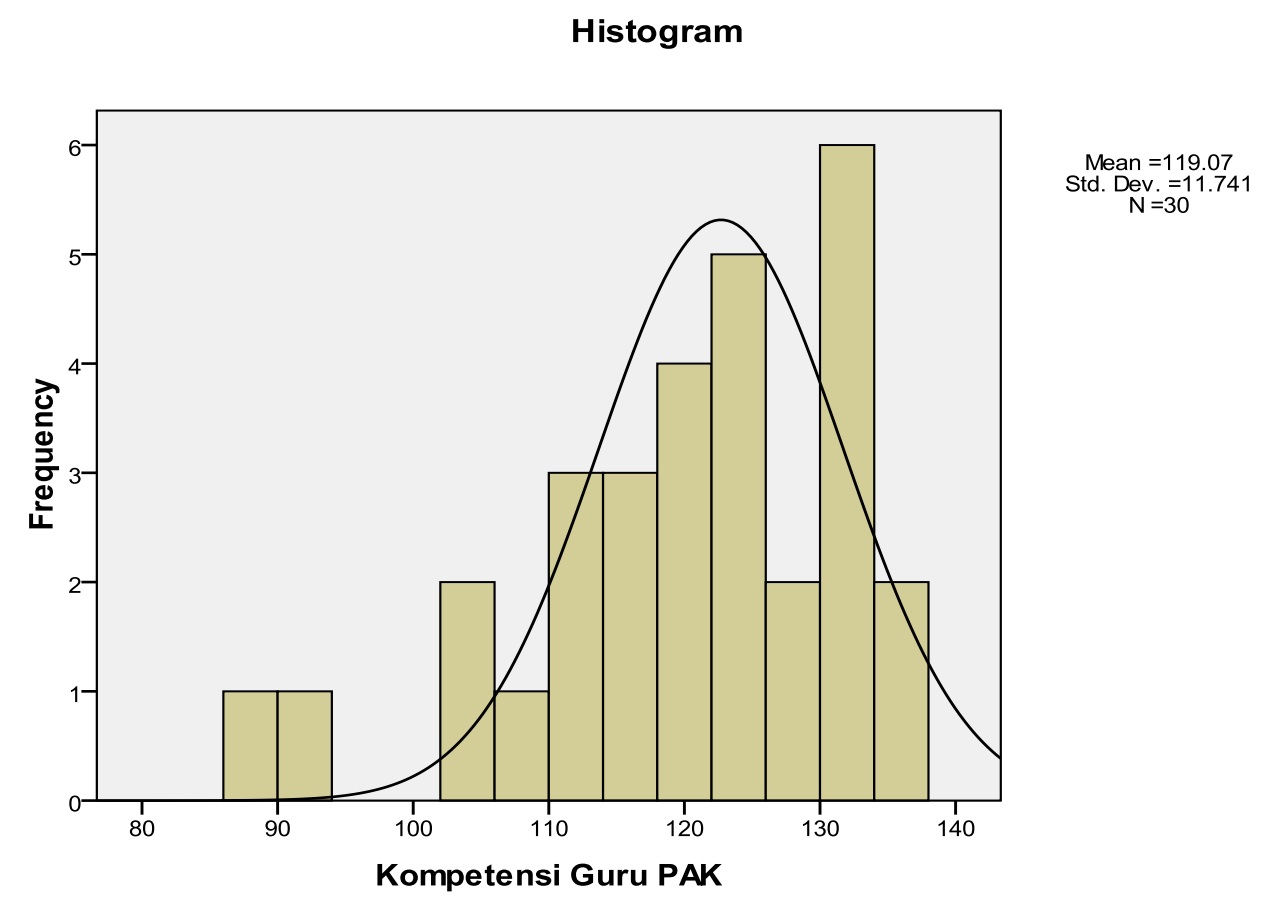

Subyek penelitian yang berada pada kelompok rata-rata sebanyak 4 orang atau 13,33\%. Subyek penelitian yang berada pada kelompok diatas rata-rata sebanyak 15 orang atau $50 \%$ sedangkan subyek penelitian yang berada pada kelompok dibawah rata-rata sebanyak 11 orang atau 36,66 \%. Kemudian kelompok rata-rata dan kelompok diatas rata-rata dijumlahkan untuk menentukan baik atau tidaknya suatu hasil penelitian. Sehingga didapatkan 19 siswa atau $63,33 \%$ menjawab rata-rata dan diatas. Dengan demikian ternyata bahwa kompetensi guru PAK menurut objek penelitian adalah baik.

\section{Kedisiplinan Guru PAK}

Berdasarkan data yang telah dikumpulkan dari variabel kompetensi guru PAK maka di peroleh nilai-nilai seperti pada tabel berikut ini: 


\section{Statistics}

Kedisiplianan Guru PAK $\left(\mathrm{X}_{2}\right)$

\begin{tabular}{|c|c|c|}
\hline \multirow[t]{2}{*}{$\mathrm{N}$} & Valid & 30 \\
\hline & Missing & 0 \\
\hline \multicolumn{2}{|l|}{ Mean } & 125.37 \\
\hline \multicolumn{2}{|c|}{ Std. Error of Mean } & 2.362 \\
\hline \multicolumn{2}{|l|}{ Median } & 131.50 \\
\hline \multicolumn{2}{|l|}{ Mode } & 133 \\
\hline \multicolumn{2}{|c|}{ Std. Deviation } & 12.936 \\
\hline \multicolumn{2}{|l|}{ Variance } & 167.344 \\
\hline \multicolumn{2}{|l|}{ Skewness } & $\mid-1.322$ \\
\hline \multicolumn{2}{|c|}{ Std. Error of Skewness } & .427 \\
\hline \multicolumn{2}{|l|}{ Kurtosis } & 1.263 \\
\hline \multicolumn{2}{|c|}{ Std. Error of Kurtosis } & .833 \\
\hline \multicolumn{2}{|l|}{ Range } & 53 \\
\hline \multicolumn{2}{|l|}{ Minimum } & 87 \\
\hline \multicolumn{2}{|l|}{ Maximum } & 140 \\
\hline \multicolumn{2}{|l|}{ Sum } & 3761 \\
\hline \multirow[t]{3}{*}{ Percentiles } & 25 & 116.25 \\
\hline & 50 & 131.50 \\
\hline & 75 & 133.50 \\
\hline
\end{tabular}

Dari tabel hasil perhitungan diatas didapatkan skor empiris antara 87 (minimim) sampai dengan 140 (maximum). Nilai Mean (nilai rata-rata) adalah 125, 37, nialai Median (nilai tengah) adalah 131, 50 dan nilai mode (nilai yang sering muncul)

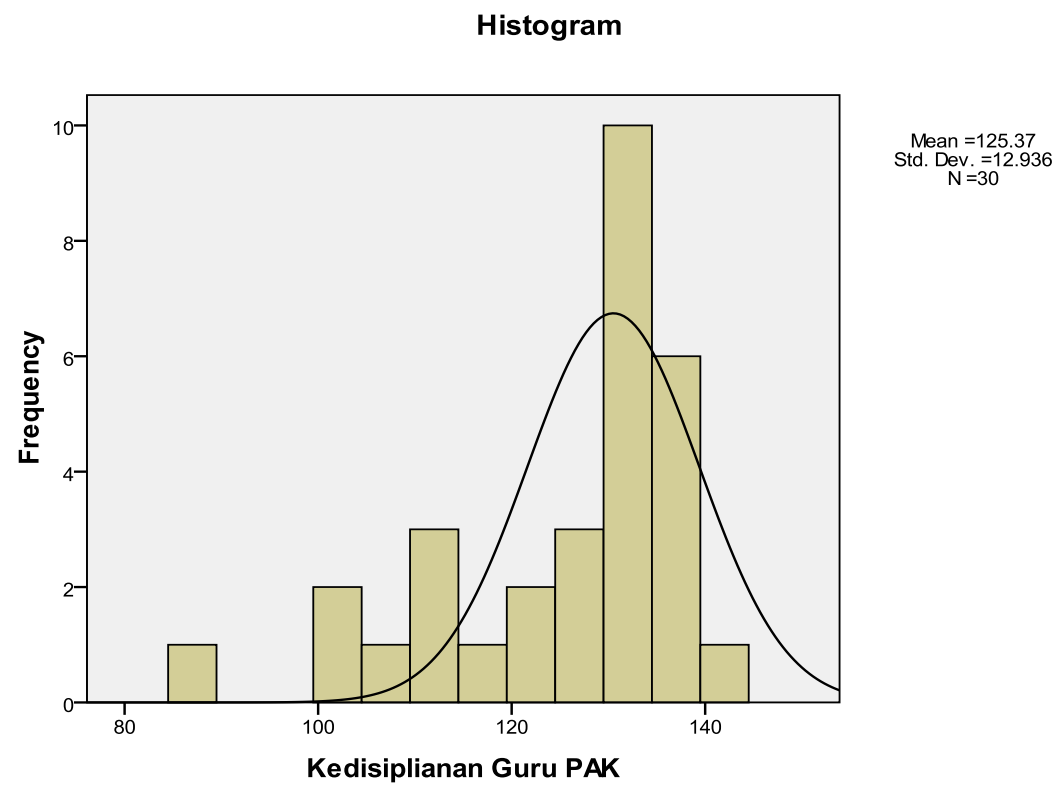

adalah 133. 
Dari histogram diatas dapat dijelaskan bahwa subyek penelitian yang berada pada kelompok rata-rata sebanyak 3 orang atau $10 \%$. Subyek penelitian yang berada pada kelompok diatas rata-rata sebanyak 17 orang atau 56,66\% sedangkan subyek penelitian yang berada pada kelompok dibawah rata-rata sebanyak 1 orang atau 33,33 $\%$. Kemudian kelompok rata-rata dan kelompok diatas rata-rata dijumlahkan untuk menentukan baik atau tidaknya suatu hasil penelitian. Sehingga didapatkan 20 siswa atau 66,66 \% menjawab rata-rata dan diatas. Dengan demikian ternyata bahwa kedisiplinan guru PAK menurut objek penelitian adalah baik.

3. Motivasi Belajar Siswa

Berdasarkan data yang telah dikumpulkan dari variabel kompetensi guru PAK maka di peroleh nilai-nilai seperti pada tabel berikut ini:

\section{Statistics}

Motivasi Belajar Siswa (Y)

\begin{tabular}{|c|c|c|}
\hline \multirow[t]{2}{*}{$\mathrm{N}$} & Valid & 30 \\
\hline & Missing & 0 \\
\hline \multicolumn{2}{|l|}{ Mean } & 130.07 \\
\hline \multicolumn{2}{|c|}{ Std. Error of Mean } & 2.794 \\
\hline \multicolumn{2}{|l|}{ Median } & 136.00 \\
\hline \multicolumn{2}{|l|}{ Mode } & 140 \\
\hline \multicolumn{2}{|c|}{ Std. Deviation } & 15.306 \\
\hline \multicolumn{2}{|l|}{ Variance } & 234.271 \\
\hline \multicolumn{2}{|l|}{ Skewness } & -1.270 \\
\hline \multicolumn{2}{|c|}{ Std. Error of Skewness } & .427 \\
\hline \multicolumn{2}{|l|}{ Kurtosis } & .918 \\
\hline \multicolumn{2}{|c|}{ Std. Error of Kurtosis } & .833 \\
\hline \multicolumn{2}{|l|}{ Range } & 60 \\
\hline \multicolumn{2}{|l|}{ Minimum } & 90 \\
\hline \multicolumn{2}{|l|}{ Maximum } & 150 \\
\hline \multicolumn{2}{|l|}{ Sum } & 3902 \\
\hline \multirow[t]{3}{*}{ Percentiles } & 25 & 125.50 \\
\hline & 50 & 136.00 \\
\hline & 75 & 140.00 \\
\hline
\end{tabular}

Dari tabel hasil perhitungan diatas didapatkan skor empiris antara 90 (minimim) sampai dengan 150 (maximum). Nilai Mean (nilai rata-rata) adalah 130,07, nialai Median (nilai tengah) adalah 136 dan nilai mode (nilai yang sering muncul) adalah 140. 


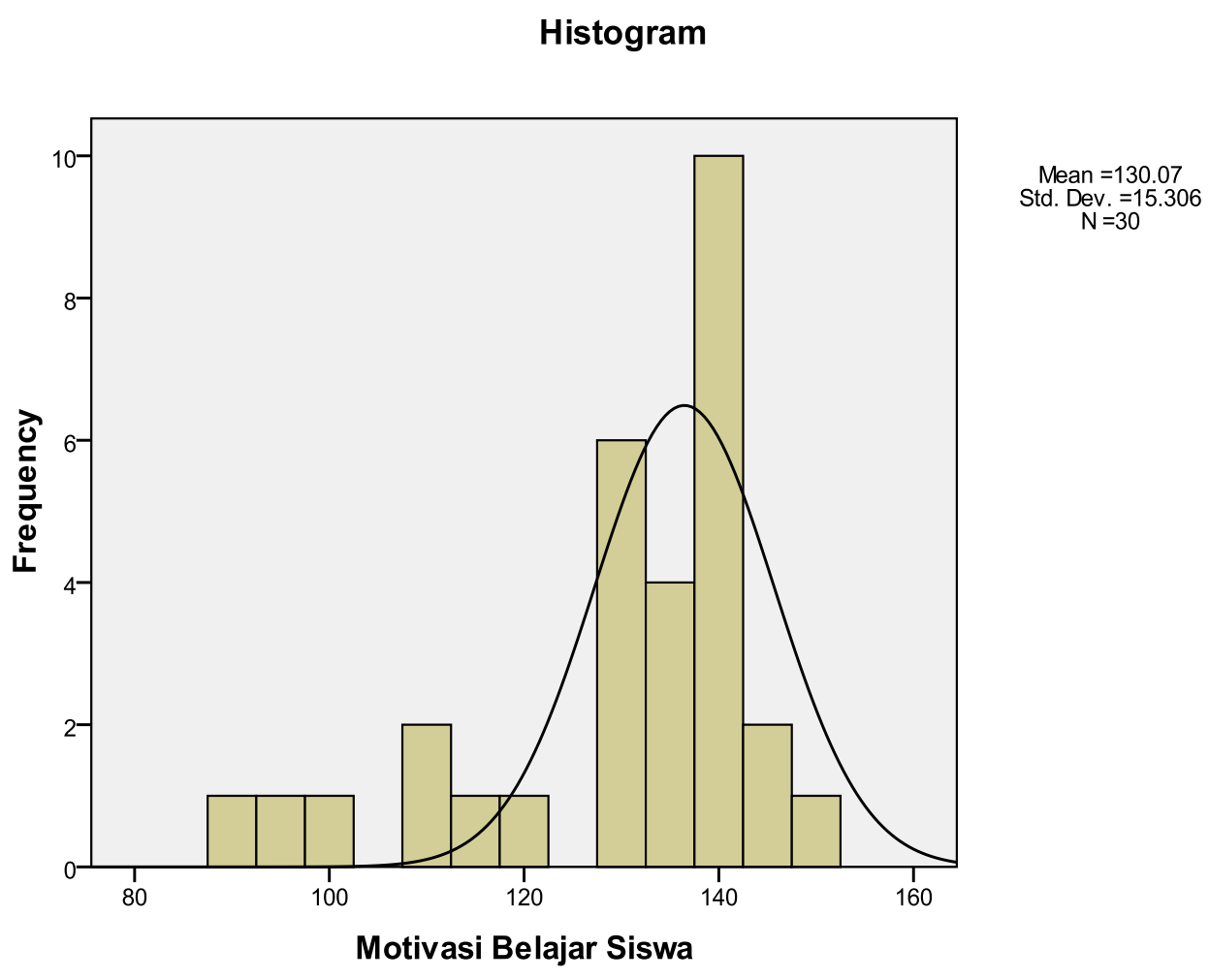

Dari histogram diatas dapat dijelaskan bahwa subyek penelitian yang berada pada kelompok rata-rata sebanyak 6 orang atau 20\%. Subyek penelitian yang berada pada kelompok diatas rata-rata sebanyak 17 orang atau 56,66\% sedangkan subyek penelitian yang berada pada kelompok dibawah rata-rata sebanyak 7 orang atau 23,33\%. Kemudian kelompok rata-rata dan kelompok diatas rata-rata dijumlahkan untuk menentukan baik atau tidaknya suatu hasil penelitian. Sehingga didapatkan 23 siswa atau 76,66\% menjawab rata-rata dan diatas. Dengan demikian ternyata bahwa motivasi belajar siswa menurut objek penelitian adalah baik.

\section{Pembahasan Hasil Penelitian}

Pertama, Berdasarkan hasil analis data diatas, maka hipoteis yang berbunyi terdapat hubungan yang positif dan signifikan antara kompetensi guru PAK dengan motivasi belajar siswa di SMK Negeri 1 Alasa Nias Utara, dapat dibuktikan dalam penelitian ini.

Kedua, Berdasarkan hasil analis data diatas, maka hipoteis yang berbunyi terdapat hubungan yang positif dan signifikan antara kedisiplinan guru PAK dengan motivasi belajar siswa di SMK Negeri 1 Alasa Nias Utara, dapat dibuktikan dalam penelitian ini.

Ketiga, Berdasarkan hasil analis data diatas, maka hipoteis yang berbunyi terdapat hubungan yang positif dan signifikan antara kompetensi dan kedisiplinan guru PAK secara bersama-sama dengan motivasi belajar siswa di SMK Negeri 1 Alasa Nias Utara, dapat dibuktikan dalam penelitian ini. 


\section{SIMPULAN}

Pertama, terdapat hubungan yang positif dan signifikan antar kompetensi guru PAK $\left(\mathrm{X}_{1}\right)$ dengan motivasi belajar siswa $(\mathrm{Y})$ SMK Negeri 1 Alasa Nias Utara.

Kedua, terdapat hubungan yang positif dan signifikan antar kedisiplinan guru PAK $\left(\mathrm{X}_{2}\right)$ dengan motivasi belajar siswa (Y) SMK Negeri 1 Alasa Nias Utara.

Ketiga, terdapat hubungan yang positif dan signifikan secara bersama antara kompetensi guru PAK $\left(\mathrm{X}_{1}\right)$ dan kedisiplinan guru PAK $\left(\mathrm{X}_{2}\right)$ dengan motivasi belajar siswa (Y) SMK Negeri 1 Alasa Nias Utara.

Sehubungan dengan hasil penelitian diatas antara kompetensi dan kedisiplinan guru PAK dengan motivasi belajar siswa signifikan antara teori dan kenyataan dilapangan, maka implikasi hasil penelitian ini adalah sebagai berikut: Pertama, jika ada peningkatan kompetensi guru PAK secara berkesinambungan, maka dapat diramalkan terjadi peningkatan motivasi belajar siswa. Kedua, jika kedisiplinan guru PAK ditingkatkan secara berkesinambungan, maka dapat diramalkan terjadi peningkatan motivasi belajar siswa. Ketiga, jika kompetensi dan kedisiplinan guru PAK ditingkatkan secara bersma-sama, maka dapat diramalkan terjadi peningkatan motivasi belajar siswa.

\section{DAFTAR PUSTAKA}

A.M. Sardiman, Interaksi dan Motivasi Belajar. Jakarta: Rajawali Pres, 2001.

Arikunto, Suharsimi, Dasar-Dasar Pendidikan. Jakarta: Bina Aksara. 1986.

Bulhke, Robert R, Ph. D. Sejarah Perkembangan Pikiran Dan Praktek Pendidikan Agama Kristen: Dari Yohanes Amos Commenius Sampai Perkembangan Pak Di Indonesia, Jakarta: BPK Gunung Mulia, 2010.

Hamalik Oemar, Proses Belajar Mengajar, Jakarta : Bumi Aksara, 2009.

Homrighausen, E. G. dan I.H. Enklaar, Pendidikan Agama Kristen (Jakarta: BPK Gunung Mulia, 1993.

Humes Leatha dan Lieke Simanjuntak, Penuntun Guru PAK Jakarta : BPK Gunung Mulia; 1998.

Imron Ali, Pembinaan Guru di Indonesia, Jakarta : Pustaka Jaya, 1995.

Musbikin Imam, Guru Yang Menakjubkan, Jogjakarta : Buku Biru, 2010.

Nainggolan, Jhon M. Guru Agama Kristen sebagai panggilan dan profesi, Bandung : Bina Media Informasi, 2007

Peraturan Menteri Pendidikan Nasional Republik Indonesia Nomor 16 tahun 2007.

Sidjabat B. S. Mengajar Secara Profesional, Bandung : Kalam Hidup, 2009.

Sinamo, Jansen, Delapan Etos Keguruan, Jakarta : Institut Darma Mahardika, 2010.

Slameto, Belajar dan faktor-faktor yang mempengaruhinya, Jakarta: Rineka Cipta, 2003.

Soetarno, H, Ilmu Keguruan Dasar-Dasar Kependidikan (Evaluasi), Bandung: Dirjendidesmen, 2002.

UU No. 14 tahun 2005 tentang guru dan dosen, bab 1 pasal 1 ayat 1

Undang-Undang No. 20 Tahun 2003 Tentang Sistem Pendidikan Nasional.

Usman Uzer, Menjadi Guru Profesional, Bandung : Rosda Karya, 2002.

Winkel, E.S. Psikologi Pendidikan dan Evaluasi Belajar. Jakarta: PT. Gramedia, 1984. 